\title{
Colorectal Cancer Surgery in Extreme Elderly Population
}

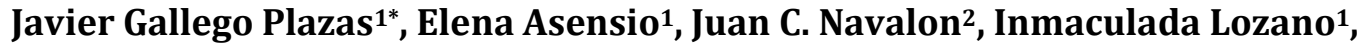 \\ Jose M. Navarro², Guillermo Ricote', Montse Olcina², Almudena Cotes', Henry M. Ore', \\ Alejandra Magdaleno1, Maria C. Ors' ${ }^{1}$, Maria J. Escudero', Miguel A. Morcillo² \\ ${ }^{1}$ Servicio de Oncología Médica, Hospital General Universitario de Elche-Hospital Vega Baja, Alicante, España \\ ${ }^{2}$ Servicio de Cirugía General, Hospital Vega Baja, Alicante, España \\ Email: ${ }^{*}$ j.gallegoplazas@gmail.com
}

Received 22 October 2014; revised 25 November 2014; accepted 10 December 2014

Academic Editor: Sibu P. Saha, University of Kentucky, USA

Copyright (C) 2015 by authors and Scientific Research Publishing Inc.

This work is licensed under the Creative Commons Attribution International License (CC BY).

http://creativecommons.org/licenses/by/4.0/

(c) () Open Access

\section{Abstract}

Background: Colorectal cancer surgery in extreme elderly population ( $\geq 80$ years) is a growing problem and a subject in question. Experiences and results in this scenario are limited. Methods: Medical records of patients $\geq \mathbf{8 0}$ years old hospitalized in General Surgery Department in Vega Baja Hospital between January 1 st 2008 and December 31st 2012 were retrospectively reviewed. Patients diagnosed with colorectal cancer (CRC) were selected. Data regarding comorbidities, treatment performed, complications and survival were collected. Results: 95 patients $(74$ colon, 21 rectum) were identified: median age 83.0 years $(80-93), 64.2 \%$ males. $93.7 \%$ of patients were operated on: median hospital and post-operative stay of 11 and 9 days, respectively; curative intention surgery $82.1 \% .4 .2 \%$ of patients were treated with interventionist procedures, and $2.1 \%$ of patients in a conservative way. $17.9 \%$ and $4.2 \%$ of patients came up with early and late complications, respectively. Early and late mortality occurred in $9.5 \%$ and $3.2 \%$ of patients, respectively. By March 2014, with a median follow up of 43.8 months, median overall survival for colorectal cancer patients was 2.7 years (95\%IC, $2.0-3.2)$. Univariaye Cox Regresion analysis revealed the presence of cardiomyopathy $(p=0.024)$, the presence of chornic kidney disease $(p=0.025)$, the presence of comorbidities (vs absence) $(0.026)$, the number of comorbidities $(0.034)$, type of admission $(p=0.001)$, treatment with surgery $(p=0.001)$ and the incidence of early $(p=0.004)$ or late complications $(p=0.023)$ associated to overall survival with statically significance. Multivariate Cox Regression analysis showed number of comorbidities (HR = 1.104; 95\%CI: 0.851 - 1.431; $p=0.456)$, treatment with surgery $(H R=4.928 ; 95 \% C I$ : $1.815-13.385 ; p=0.002)$, programmed admission into hospital (HR $=2.316 ; 95 \% \mathrm{CI}$ : $1.298-4.133 ; \mathrm{p}=0.004)$, and the incidence of late complications (HR = 4.629; 95\%CI: $1.279-16.750 ; \mathrm{p}=0.020$ ) independently associated with over-

\footnotetext{
${ }^{*}$ Corresponding author.
}

How to cite this paper: Plazas, J.G., Asensio, E., Navalon, J.C., Lozano, I., Navarro, J.M., Ricote, G., Olcina, M., Cotes, A., Ore, H.M., Magdaleno, A., Ors, M.C., Escudero, M.J. and Morcillo, M.A. (2015) Colorectal Cancer Surgery in Extreme Elderly Population. Journal of Cancer Therapy, 6, 12-20. http://dx.doi.org/10.4236/jct.2015.61002 
all survival. Interaction test between number of comorbidities and early complication was performed (HR = 1.453; 95\%CI: $0.971-2.175 ; p=0.070)$. Conclusions: In our experience surgery for CRC patients may increase overall survival even in an extreme elderly population ( $\geq 80$ years). Nevertheless when considering surgery for CRC in this subgroup of patients, factor such as type of admission into hospital and comorbidities should be taken into account in order to optimize treatment results in the effort to individualize CRC management in this growing population.

\section{Keywords}

Colorectal, Cancer, Surgery, Elderly

\section{Introduction}

Surgery is the key curative treatment for colon and rectal cancer. Additionally, palliative surgery offers valuable options to increase quality of life of patients. Currently, surgical outcome and quality of cancer care are at the top of the list of "improvement of care" projects. From large observational research, we know that wide variations in patterns of care and outcome exist in the field of surgical oncology [1].

Oncologists and surgeons managing patients colorectal cancer (CRC) must recognize that approximately $60 \%$ of their patients are $>70$ years of age and $43 \%$ are $>75$ [2]. As a result of an increasing number of elderly, more octogenarians are presented to the surgeon for operation. From cancer registry data (EUROCARE-4), we know that survival over time was more pronounced in younger colorectal patients than in elderly [3]. Because the group of older patients is very heterogeneous with regard to co-morbidities and fitness, it is difficult to identify patients that have a high risk of adverse outcome after colorectal cancer surgery. Age matters, but elderly patients can be operated upon with acceptable morbidity and mortality in elective setting.

Despite recent studies demonstrating the feasibility of the Comprehensive Geriatric Assessment (CGA) in oncology, adoption as the standard of care has been slow because of lack of resources, difficulties with interpretation of results, and challenges in implementing targeted interventions in specialty clinic settings such as oncology. A short, simple, validated screening procedure could quickly identify patients who are at risk for morbidity or death in the oncology clinic. Partnering with geriatricians, geriatric oncology or geriatric surgery consultative service can help provide geriatric assessment. On the other hand, instruments developed for this are unfortunately still time consuming and not very practical.

Identifying "frail" octogenarians is of utmost importance to acquire a realistic prognosis of cancer surgery.

In the past, some studies have shown that postoperative morbidity and mortality are associated with other patients and surgery related factors rather than exclusively to the patients' age [4]-[9]. Nevertheless, data are limited, especially when we consider the extreme elderly cohort of patients ( $\geq 80$ years of age).

A retrospective study of CRC surgery in patients $\geq 80$ years of age was carried out in order to provide more evidence of the specific management of this subgroup of patients, to explore the factors influencing surgery related morbidity and mortality, and to evaluate the real life impact of this treatment on survival.

\section{Methods}

Registry data from Vega Baja Hospital were retrospectively reviewed in order to obtain a list of patients $\geq 80$ years of age admitted into Surgery Department between January 1, 2008 and December 31, 2012. Each patient file was studied and data regarding reason for admission, type of admission, comorbidities, management, complications, and follow up were registered. Patients were grouped in oncologic and non oncologic related diagnosis. Patients with oncologic related diagnosis were subsequently splitted into groups depending on the primary tumour. Analysis of patients with diagnosis of CRC is the focus of this publication.

Previous history of hypertension, lipid disorder, diabetes mellitus was registered. Heart factors included previous myocardial infarction, congestive heart failure, and hypertension. Lung factors included chronic lung disease, pneumonia, and previous lung resection. Kidney factors included chronic kidney disease. Liver factors included chronic liver failure. Previous cerebrovascular disease included history of cerebrovascular injury. Congnitive disorders included dementia of any etiology. Preoperative evaluations included cardiovascular, pulmo- 
nary, renal, hepatic, cerebrovascular, cognitive, and metabolic assessments. Median hospital stay was calculated. Type of admission was categorized as programmed or emergency. Treatment to patients was divided into surgical, interventional, and conservative. When surgical treatment applied surgical technique was registered, median postoperative hospital stay was calculated, planned and final intention of surgery were evaluated, and need of reoperation was recorded. In case of interventional management, interventional procedure was registered.

Early and late complications, and readmission into hospital were studied. Complications included: infectious, dehiscence, multiorganic failure, scar related hematoma, cardiovascular, respiratory, cerebrovascular, hernia, fistula, hemorrhage, poor evolution cause of admission, non resolved cause of admission, and unknown. Early and late mortality was studied and status at study follow up cut point was registered as healthy alive, alive with disease, cancer related death, surgery related death, other causes related death, and lost to follow up.

Statiscal analysis was carried out using SPSS Statistics 22. Continues random variables were summarized as central tendency and dispersion measures (median, range, mean, confidence interval). The quantitative variables were expressed as percentages. The confidence interval was calculated at $95 \%$ of confidence.

Kaplan-Meier and live tables were used to analyse the Overall Survival. Comparison between curves was performed using the log rank test. In addition, a multiple regression analysis for Overall Survival adjusting by major prognostic factors was performed.

\section{Results}

Between January 1, 2008 and December 31, 2012, 451 patients $\geq 80$ years of age were admitted into General Surgery Department in Vega Baja Hospital, a third level hospital with a target median general population during that period of 170,051 citizens. 133 out of 451 patients (29.5\%) were admitted into hospital due to a cancer related diagnosis, while 318 patients (70.5\%) were admitted due to non-oncologic related diagnosis: 29.6\% (94) hernia, 38.7\% (123) biliary tract related diseases, 10.7\% (34) non cancer related intestinal occlusion, being the most frequent causes. Patients admitted due to cancer related diagnosis were mainly distributed as follows (>5\%): 55.6\% (74) colon cancer, 15.8\% (21) rectal cancer, 12\% (16) breast cancer, and 7.5\% (10) gastric cancer.

Median age of patients with CRC (95) as 83.0 (80 - 93); 64.2\% (61) male and 35.8\% (34) female. For colon cancer patients (74), median age was 83.5 (80 - 93); 68.9\% (51) male, $31.1 \%$ (23) female. For rectal cancer patients (21), median age was 83.0 (81 - 92); 47.6\% (10) male, 52.4\% (11) female. There were no statistically significant differences between colon and rectal cancer patients related to age or gender.

Comorbidities of patients with CRC were distributed as follows: hypertension 66.3\% (63), lipid disorder $22.1 \%$ (21), heart disease $28.4 \%$ (27), lung factors $16.8 \%$ (16), diabetes mellitus $21.1 \%$ (20), cerebrovascular disease $10.5 \%$ (10), chronic kidney disease $8.4 \%$ (8), cognitive disorder $12.6 \%$ (12). Except for hypertension (colon cancer $71.6 \%$, rectal cancer $47.6 \%$, p $=0.040$ ) there were no statistically significant differences in distribution of comorbidities between colon and rectal cancer patients.

Type of admission into hospital was programmed in 65.3\% (62) and as emergency entrance in the rest of patients (34.7\%, 33 patients). All admissions for rectal cancer were programmed, while $44.6 \%$ (33) of colon cancer patients had unscheduled admission. There was statistically significant difference regarding type of admission between colon and rectal cancer patients ( $\mathrm{p}<0.001)$. Median hospital stay was 11 days $(1-56)$. For colon cancer median hospital stay was 11 days (3 - 56); for rectal cancer median hospital stay was 10 days (1 - 21). There was statistically significant difference in median stay between colon and rectal cancer patients $(p=0.0188)$.

Patients were treated with surgery in $93.7 \%$ of cases (89), with interventional procedures in $4.2 \%$ of cases (4), and in a conservative way in $2.1 \%$ of cases (2). No rectal cancer patients were managed with interventional procedures. No differences were observed in the frequency of colon and rectal cancer patients treated with surgery or in a conservative fashion. When surgery was applied, right hemicolectomy (26.3\%, 25 patients), sigmoidectomy (22.1\%, 21 patients) and low anterior resection (11.6\%, 11 patients) were the three most common surgical procedures. Initial intention of surgery was curative in $82.1 \%$ patients (78), whereas was palliative in $10.5 \%$ of patients (10). Surgery performed was curative in $81.0 \%$ of patients (77), and palliative in $11.6 \%$ of patients (11). Palliative surgery was more common in patients with colon cancer (13.5\%, 10 patients) than in patients with rectal cancer $(4.8 \%, 1$ patient). There was no statistically significant difference in curative vs paliative surgery between colon and rectal cancer patients $(p=0.683)$. Median postoperative stay was 9 days $(0-55)$ for all CRC patients: 10 days $(0$ - 55) for colon cancer, $9(1-20)$ for rectal cancer. There was no statitiscally 
significant difference in median postoperative stay between colon and rectal cancer patients ( $\mathrm{p}=0.1723$, Wilcoxon Test). All interventional manouvres were related to stent placement.

Early complications related to management occurred in $17.9 \%$ of CRC patients (17): $20.3 \%$ of colon cancer patients (15), and $9.5 \%$ of rectal cancer patients (2). There was no statistically significant difference in early complications between colon and rectal cancer patients. Late complications occurred in $4.2 \%$ of patients (4) with no differences in incidence between colon and rectal cancer patients. The six more frequent complications were: multiorganic failure in $4.2 \%$ of patients (4), dehiscence in $3.2 \%$ of patients (3), fistulae in $2.1 \%$ of patients (2), cardiac in $2.1 \%$ of patients (2) and respiratory in $2.1 \%$ of patients (2). Multiorganic failure, fistulae and cardiac complications were only incident in colon cancer patients. Postoperative stay associated with complications was as follows: multiorganic failure 9 days (3 - 18), dehiscence 13.33 days $(9$ - 16), fistulae 22 days (16 - 28), cardiac 13.5 days (10 - 17), respiratory 37.5 (20 - 55). Readmissions occured in $4.2 \%$ of patients (4): 3 patients with colon cancer, 1 patient with rectal cancer.

By March 2014, with a median follow up of 43.8 months, 37.9\% of patients were alive free of relapse, $2.1 \%$ were alive with disease, $26.3 \%$ had died of cancer, $10.5 \%$ had died of surgery related complications, and $23.2 \%$ of patients had died of other causes. Median overall survival for colorectal cancer patients was 2.7 years (95\%CI, 2.0 - 3.2) (Figure 1) (Table 1). In subgroup analysis median overall survival for colon cancer patients was 2.3 years, and 3.4 years for rectal cancer patients. No statistically significant difference was observed in survival between colon and rectal cancer patients $(\mathrm{p}=0.230)$.

Median overall survival for colorectal cancer patients, according to type of admission, was 3.4 years for scheduled admission and 1.1 years for emergency admission. There was statistically significant difference in median overall survival between programmed and emergency admission $(\mathrm{p}<0.0001)$.

Univariaye Cox Regresion analysis was performed in order to test variables with potential impact on overall survival. Regarding comorbidities, the presence of heart factors $(\mathrm{p}=0.024)$ and the presence of chronic kidney disease $(\mathrm{p}=0.025)$ were associated to overall survival reaching statistically significance. In univariate analysis, the presence of comorbidities (vs absence) (0.026) and the number of comorbidities $(0.034)$ were also statisti-

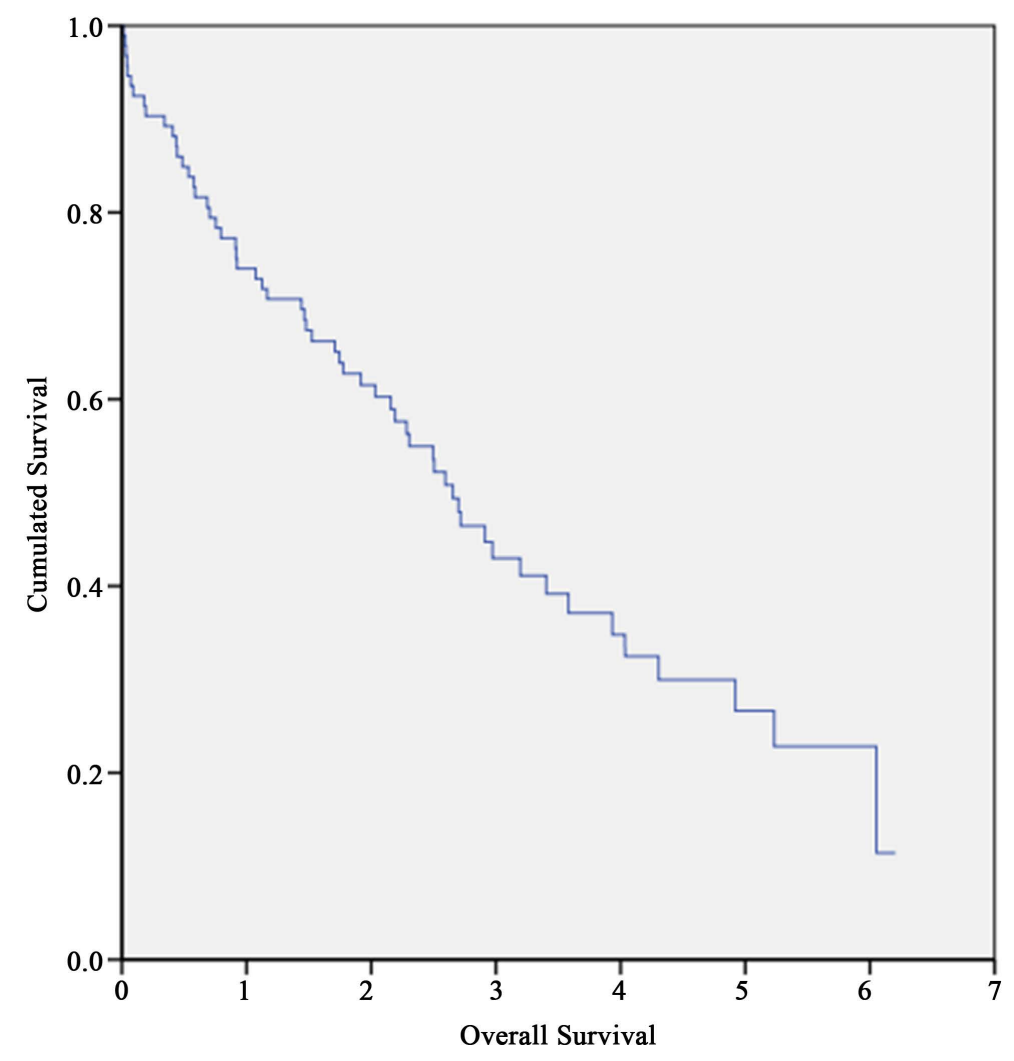

Figure 1. Overall survival in colorectal cancer patients $\geq 80$ years. 
Table 1. Overall Survival in colorectal cancer patients $\geq 80$ years.

\begin{tabular}{|c|c|c|}
\hline \multicolumn{3}{|c|}{ Overall Survival Colorectal Cancer } \\
\hline & Value & $95 \% \mathrm{CI}$ \\
\hline Media & 3.0 years & $2.5-3.5$ years \\
\hline Median & 2.7 years & 2.0 - 3.2 years \\
\hline 25 percentil & 5.2 years & 4.0 - 6.4 years \\
\hline 75 percentil & 0.9 years & 0.3 - 1.5 years \\
\hline 1 year Overall Survival & $74.1 \%$ & $65.1 \%-83.0 \%$ \\
\hline 2 years Overall Survival & $61.3 \%$ & $51.2 \%-71.4 \%$ \\
\hline 3 years Overall Survival & $43.0 \%$ & $32.1 \%-53.9 \%$ \\
\hline 4 years Overall Survival & $35.2 \%$ & $23.9 \%-46.5 \%$ \\
\hline 5 years Overall Survival & $27.1 \%$ & $15.2 \%-38.9 \%$ \\
\hline 6 years Overall Survival & $22.1 \%$ & $9.1 \%-35.2 \%$ \\
\hline 7 years Overall Survival & $7.4 \%$ & $0 \%-24.6 \%$ \\
\hline
\end{tabular}

cally significantly associated to overall survival. Neither length of hospital stay nor length of postoperative stay were associated to overall survival. Finally, in univariate analysis, type of admission $(p=0.001)$, treatment with surgery $(p=0.001)$ and the incidence of early $(p=0.004)$ or late complications $(p=0.023)$ were associated to overall survival with statically significance (Table 2).

Multivariate Cox Regression analysis was carried out, based on univariate analysis, in order to test variables independently associated to overall survival. The following variables were included in multivriate analysis: number of comorbidities (HR = 1.104; 95\%CI: $0.851-1.431$; $\mathrm{p}=0.456)$, treatment with surgery $(\mathrm{HR}=4.928$; 95\%CI: 1.815 - 13.385; $\mathrm{p}=0.002)$, programmed admission into hospital for scheduled surgery $(\mathrm{HR}=2.316$; 95\%CI: $1.298-4.133 ; \mathrm{p}=0.004)$, the incidence of early $(\mathrm{HR}=1.578$; 95\%CI: $0.586-4.398 ; \mathrm{p}=0.383)$ or late complications ( $\mathrm{HR}=4.629$; 95\%CI: $1.279-16.750 ; \mathrm{p}=0.020)$, and also the interaction between number of comorbilities and early complication (HR $=1.453$; 95\%CI: 0.971 - 2.175; $\mathrm{p}=0.070$ ) (Table 3).

\section{Discussion}

Colorectal cancer (CRC) is the third leading cause of cancer death worldwide, representing $10 \%$ of cancer diagnoses and deaths [10]. More than 800,000 new cases, including 300,000 in the US and Europe alone are diagnosed annually [11]. CRC is primarily a disease of the elderly, as confirmed by a median age at diagnosis of 71 years in the US [12]. Forty percent of cases occur in patients $>75$ years of age [13], and the incidence increases with advancing age, doubling every 7 years in patients aged $>50$ years [12]. Societal and medical burdens of CRC will only worsen over coming decades as the demographic proportion of elderly individuals continues to grow. Women and men in the US aged 60, 70, and 80 years can expect to live an additional 24 and 20.8, 16.2 and 13.7, and 9.8 and 8.2 years, respectively [14]. In France, the expected mean number of years remaining for women and men at those ages are 26.47 and 21.48, 17.88 and 14.11, and 10.28 and 8.10, respectively [15] [16]. Survival for patients with CRC continues to improve. A recent analysis of trends in a French population found an increase in the 5-year survival rate among patients aged $>75$ years from 1976-1987 to 1988-1999 (47.1\% versus 53.6\%, respectively; $\mathrm{p}<0.001)$ [17], attributed primarily to an increase in the number of patients being resected for cure and to a decrease in postoperative mortality, rather than to adjuvant chemotherapy, which was used much less frequently in older than younger patients.

Most of the available publications related to elderly patients with CRC focus their analysis in patients over the age of 70 - 75 years. Nevertheless our interest was centered on more elderly population, once we realize our daily practice involves much older patients and there is an unsatisified need of guidance for management of this growing subgroup. Our series of patients stands out as one with de highest median age reported, 83.0 years (80 93), proving the fact of the assumption of assistance to this so-called extreme elderly patients. 
Table 2. Univariate analysis.

\begin{tabular}{|c|c|c|c|c|}
\hline Variable & $\mathbf{N}$ & HR & $95 \% \mathrm{CI}$ & p-value \\
\hline \multicolumn{5}{|l|}{ Sex } \\
\hline Male & 60 & 1 (reference) & & \\
\hline Female & 33 & 0.933 & $0.544-1.601$ & 0.802 \\
\hline Age & 93 & 1.053 & $0.968-1.145$ & 0.228 \\
\hline \multicolumn{5}{|l|}{ Colon/Rectal } \\
\hline Colon & 73 & 1 (reference) & & \\
\hline Rectal & 20 & 0.677 & $0.357-1.284$ & 0.232 \\
\hline \multicolumn{5}{|l|}{ Hypertension } \\
\hline Yes & 61 & 1 (reference) & & \\
\hline No & 32 & 0.859 & $0.485-1.522$ & 0.602 \\
\hline \multicolumn{5}{|l|}{ Lipid disorder } \\
\hline Yes & 20 & 1 (reference) & & \\
\hline No & 73 & 1.013 & $0.535-1.920$ & 0.967 \\
\hline \multicolumn{5}{|l|}{ Heart factors } \\
\hline Yes & 25 & 1 (reference) & & \\
\hline No & 68 & 0.525 & $0.301-0.917$ & 0.024 \\
\hline \multicolumn{5}{|l|}{ Lung factors } \\
\hline Yes & 16 & 1 (reference) & & \\
\hline No & 77 & 0.776 & $0.379-1.591$ & 0.490 \\
\hline \multicolumn{5}{|l|}{ Diabetes Mellitus } \\
\hline Yes & 19 & 1 (reference) & & \\
\hline No & 74 & 0.670 & $0.358-1.254$ & 0.211 \\
\hline \multicolumn{5}{|l|}{ Cerebrovascular disease } \\
\hline Yes & 10 & 1 (reference) & & \\
\hline No & 83 & 1.160 & $0.497-2.711$ & 0.731 \\
\hline \multicolumn{5}{|l|}{ Chronic kidney disease } \\
\hline Yes & 8 & 1 (reference) & & \\
\hline No & 85 & 0.397 & $0.177-0.889$ & 0.025 \\
\hline \multicolumn{5}{|l|}{ Cognitive disorder } \\
\hline Yes & 12 & 1 (reference) & & \\
\hline No & 81 & 0.637 & $0.320-1.267$ & 0.199 \\
\hline \multicolumn{5}{|l|}{ Comorbidities } \\
\hline Yes & 77 & 1 (reference) & & \\
\hline No & 16 & 0.350 & $0.139-0.884$ & 0.026 \\
\hline Number of comorbidities & 93 & 1.239 & $1.016-1.511$ & 0.034 \\
\hline \multicolumn{5}{|l|}{ Programmed admission } \\
\hline Yes & 60 & 1 (reference) & & \\
\hline No & 33 & 2.545 & $1.501-4.317$ & 0.001 \\
\hline \multicolumn{5}{|l|}{ Surgery } \\
\hline Yes & 87 & 1 (reference) & & \\
\hline No & 6 & 5.003 & $2.015-12.420$ & 0.001 \\
\hline Hospital stay (days) & 93 & 1.014 & $0.991-1.038$ & 0.238 \\
\hline \multicolumn{5}{|l|}{ Early complication } \\
\hline Yes & 17 & 2.388 & $1.311-4.347$ & 0004 \\
\hline No & 76 & 1 (reference) & & 0.004 \\
\hline \multicolumn{5}{|l|}{ Late complication } \\
\hline Yes & 4 & 4.055 & $1.216-4.055$ & 0.023 \\
\hline No & 89 & 1 (reference) & & \\
\hline
\end{tabular}

Abbreviations: N, number of patients; HR, hazard ratio; CI, confidence interval. 
Table 3. Multivariate analysis.

\begin{tabular}{|c|c|c|c|}
\hline Variable & Sig (Wald) & $\operatorname{Exp}(B)$ & $95 \% \mathrm{CI}$ \\
\hline Number of comorbidities & 0.456 & 1.104 & $0.851-1.431$ \\
\hline $\begin{array}{c}\text { Programmed admission } \\
\text { Yes } \\
\text { No }\end{array}$ & 0.004 & $\begin{array}{l}1 \text { (reference) } \\
2.316\end{array}$ & $1.298-4.133$ \\
\hline $\begin{array}{l}\text { Surgery } \\
\text { Yes } \\
\text { No }\end{array}$ & 0.002 & $\begin{array}{l}1 \text { (reference) } \\
\quad 4.928\end{array}$ & $1.815-13.385$ \\
\hline $\begin{array}{c}\text { Early complication } \\
\text { Yes } \\
\text { No }\end{array}$ & 0.383 & $\begin{array}{c}1.578 \\
1 \text { (reference) }\end{array}$ & $0.566-4.398$ \\
\hline $\begin{array}{c}\text { Late complication } \\
\text { Yes } \\
\text { No }\end{array}$ & 0.020 & $\begin{array}{l}4.629 \\
1 \text { (reference) }\end{array}$ & $1.279-16.750$ \\
\hline Number of comorbidities ${ }^{*}$ Early complication & 0.070 & $\begin{array}{c}1.453 \\
1 \text { (reference) }\end{array}$ & $0.971-2.175$ \\
\hline
\end{tabular}

Abbreviations: Sig (Wald), p-value; Exp (B), HR; CI, Confidence Interval; "Interaction Test.

Patients with comorbidities present considerable challenges to cancer management because they are not well studied in the literature and are often excluded from clinical trials. Because the incidence of both chronic disease and cancer increases with age, the prevalence of comorbidities is especially high in elderly cancer patients [18] [19]. More than half of all cancer patients age 50 to 74 years have at least one comorbidity, and this proportion rises to nearly two thirds in those age 75 and older [20]. As the age distribution of the population shifts, it is expected that there will be an increasing number of older patients with comorbidities who will be diagnosed with and treated for cancer [18] [21]. The presence of comorbidities adds complexity to cancer management because it may influence prognosis and treatment decisions and affect overall goals of care. It is known that patients with a high burden of comorbidity at the time of cancer diagnosis have a higher mortality rate [22]. However, the underlying mechanisms for this observation are poorly understood. Comorbidity may affect outcomes at various points during a patient's clinical course, from diagnosis to treatment. For example, a single comorbidity may influence a patient's outcome by delaying cancer diagnosis, decreasing use of chemotherapy, increasing treatmentrelated toxicities, or acting as a competing cause of death [23]. Furthermore, the effect of comorbidity on outcomes may be confounded by factors such as age [24], performance status [24] [25], and tumor-related factors [26]. In comparison with age, comorbidity is a more complicated area of study because its assessment is multidimensional, requiring consideration of a range of conditions as well as their prognostic impact. To capture comorbidity more quantitatively, index systems have been developed that generate an overall score on the basis of a list of medical conditions with weighted or graded severity values.

In our experience, in the univariate Cox Regression analysis there were several statistical significant variables related to overall survival, age, colon/rectal, number of comorbilities, type of admission, surgery, days of stay, type of comorbilities. Taking into account the Univariate Cox Regression analysis, the non scheduled admission into hospital had higher risk of death that the patients with scheduled admission (HR $=2.545$; 95\%CI: 1.501 4.317). Intestengly, in our series there was a high proportion of nonelective surgery for colon cancer. $44.6 \%$ of patients with colon cancer were admitted into hospital as an emergency, a proportion clearly over the $15 \%$ expected to be colon cancers with obstructive symptoms. In the other hand, none patients with rectal cancer in our series had an emergency entrance, and all surgeries performed for rectal cancer were elective. The fact of this statistically significant difference in type of admission between colon and rectal cancer may have well influenced the statistically significant different median hospital stay [11 (3 - 56) days for colon cancer, 10 (1 - 21) days for rectal cancer, $\mathrm{p}=0.0188$ ] in both groups as well as other subgroup analysis of the study. The same could have applied for the existing difference in median postoperative hospital stay between colon and rectal cancer patients [10 (0 - 55) days for colon cancer, 9 (1 - 20) days for rectal cancer] although in this particular analysis the difference did not reach statistically significant difference ( $p=0.1723$, Wilcoxon Test).

Taking into account the Univariate Cox Regression analysis, the non surgery managed patients had higher risk of death that the patients managed with surgery (HR = 5.003; 95\%CI: 2.015 - 12.420). Patients in our series 
were mainly managed with surgery (93.7\%), independently of colon or rectal primary. Interventional procedures in our patients (4.2\%) were all related to stent placement. Stenting seems to have a place in the palliative setting if the life expectancy of the patient is restricted (less than 3 months). The elderly frail patients with a short stenosis that is technically considered to be a "stentable" lesion is probably a good candidate for a stent as bridge to surgery in the curative setting, rather than acute resection. In healthy patients (i.e. below 70 years of age without significant co-morbidities), acute resection should be considered as standard of care. For patients not suitable for stenting and with a high operative risk, diverting colostomy is a suitable treatment option [1]. In our series, the high proportion of curative intent surgeries (81.1\%), specially in colon cancer patients (86.5\%), helps to justify the low proportion of stent placements. No doubt, a more accute evaluation of frailty of patients evaluating age, comorbidities, functional status and other aspects would have helped to consider if more interventional procedures shoul have been performed.

In our experience, in the multivariate Cox Regression analysis the following variables influenced overall survival: non scheduled admission into hospital (HR = 2.316; 95\%CI: $1.298-4.133$; $\mathrm{p}=0.004$ ), non surgery management (HR = 4.928; 95\%CI: 1.815 - 13.385; $\mathrm{p}=0.002)$, and incidence of late complications (HR = 4.629; 95\%CI: $1.279-16.750 ; \mathrm{p}=0.020$ ). Previous experiences had shown that postoperative morbidity and mortality were associated with other patients and surgery related factors rather than exclusively to the patients' age [4]-[9]. As an example of colorectal cancer surgery, we learned that the presence of at least two significant co-morbidities has a substantial effect in patients older than 70 years, resulting in a mortality of $16.2 \%$ when compared with $8.6 \%$ in a younger cohort [6] [27]. Emergency surgery even added up the risks to $41 \%$ in patients aged over 80 years in the Dutch nationwide population-based study [8]. One-year postsurgical mortality was even 51.2\% in patients aged 80 years and older in an English cohort, indicating that age was an independent determinant of mortality in risk adjusted regression analyses [9].

Considering median age of our cohort of patients 83.0 (80 - 93) and median overall survival 2.7 years (CI $95 \%, 2.7$ - 3.2) we would stimate median life expectancy for patients over 80 years treated for CRC in our series of 85.7 years, clearly above calculated life expectancy either for males or females in Spain.

Limitations to our study are its retrospective design, sample size, and the fact of being a monocentric experience. Hence we add more leve IV evidence in a scenerario where prospective multicentric studies with homogeneusly collected data and with well represented subgroups of patients are convenient in order to come to firm conclussions which could guide treatment algorithms for this increasing clinical situation.

\section{Conclusion}

In conclusion, in our experience surgery for CRC patients may increase overall survival even in an extreme elderly population ( $\geq 80$ years). Nevertheless when considering management of CRC in this subgroup of patients, factors such as type of admission into hospital, surgical management, and probability of incidence of late complications should be taken into account in order to optimize treatment results in the effort to individualize CRC management in this growing population.

\section{References}

[1] van de Velde, C.J.H., Boelens, P.G., Tanis, P.J., et al. (2014) Experts Reviews of the Multidisciplinary Consensus Conference Colon and Rectal Cancer 2012: Science, Opinions and Experiences from the Experts of Surgery. European Journal of Surgical Oncology, 40, 454-468. http://dx.doi.org/10.1016/j.ejso.2013.10.013

[2] http://www.ncin.org.uk/cancer_information_tools/ukcis

[3] Brenner, H., Bouvier, A.M., Foschi, R., et al. (2012) Progress in Colorectal Cancer Survival in Europe from the Late 1980s to the Early 21st Century: The EUROCARE Study. International Journal of Cancer, 131, 1649-1658. http://dx.doi.org/10.1002/ijc.26192

[4] Jensen, H.E., Nielsen, J. and Balslev, I. (1970) Carcinoma of the Colon in Old Age. Annals of Surgery, 171, $107-115$. http://dx.doi.org/10.1097/00000658-197001000-00016

[5] Irvin, T.T. (1988) Prognosis of Colorectal Cancer in the Elderly. British Journal of Surgery, 75, 419-421.

[6] Boyd, J.B., Bradford Jr., B. and Watne, A.L. (1980) Operative Risk Factors of Colon Resection in the Elderly. Annals of Surgery, 192, 743-746. http://dx.doi.org/10.1097/00000658-198012000-00009

[7] Dekker, J.W., Gooiker, G.A., Bastiaannet, E., et al. (2014) Cause of Death the First Year after Curative Colorectal Cancer Surgery; a Prolonged Impact of the Surgery in Elderly Colorectal Cancer Patients. European Journal of Sur- 
gical Oncology, 40, 1481-1487. http://dx.doi.org/10.1016/j.ejso.2014.05.010

[8] Kolfschoten, N.E., Wouters, M.W., Gooiker, G.A., et al. (2012) Nonelective Colon Cancer Resections in Elderly Patients: Results from the Dutch Surgical Colorectal Audit. Digestive Surgery, 29, 412-419. http://dx.doi.org/10.1159/000345614

[9] Mamidanna, R., Eid-Arimoku, L., Almoudaris, A.M., et al. (2012) Poor 1-Year Survival in Elderly Patients Undergoing Nonelective Colorectal Resection. Diseases of the Colon \& Rectum, 55, 788-796. http://dx.doi.org/10.1097/DCR.0b013e3182585a35

[10] Jemal, A., Murray, T., Ward, E., et al. (2005) Cancer Statistics, 2005. CA: A Cancer Journal for Clinicians, 55, 10-30. http://dx.doi.org/10.3322/canjclin.55.1.10

[11] Goldberg, R.M., Tabah-Fisch, I., Bleiberg, H., de Gramont, A., Tournigand, C., Andre, T., et al. (2006) Pooled Analysis of Safety and Efficacy of Oxaliplatin plus Fluorouracil/Leucovorin Administered Bimonthly in Elderly Patients with Colorectal Cancer. Journal of Clinical Oncology, 24, 4085-4091. http://dx.doi.org/10.1200/JCO.2006.06.9039

[12] Ries, L.A.G., Harkins, D., Krapcho, M., et al., Eds. (2003) Contents of the SEER Cancer Statistics Review, $1975-2003$. National Cancer Institute, Bethesda. http://seer.cancer.gov/csr/1975_2003/

[13] Edwards, B.K., Howe, H.L., Ries, L.A.G., Thun, M.J., Rosenberg, H.M., Yancik, R., et al. (2002) Annual Report to the Nation on the Status of Cancer, 1973-1999, Featuring Implications of Age and Aging on US Cancer Burden. Cancer, 94, 2766-2792. http://dx.doi.org/10.1002/cncr.10593

[14] Minino, A.M., Heron, M.P., Murphy, S.L., et al. (2007) Deaths: Final Data for 2004. National Vital Statistics Reports, 55, 1-119.

[15] (2007) Life Expectancy by Selected Ages since 1946: Females. Institut National D’tudes Démographiques, Paris. http://www.ined.fr/fichier/t_telechargement/11151/telechargement_fichier_fr_telechargement_fichier_fr_sd2004_t69es p_fm.1.xls

[16] (2007) Life Expectancy by Selected Ages since 1946: Males. Institut National D’tudes Démographiques, Paris. http://www.ined.fr/fichier/t_telechargement/11152/telechargement_fichier_fr_telechargement_fichier_fr_sd2004_t69es p_fm.1.xls

[17] Mitry, E., Bouvier, A.M., Esteve, J. and Faivre, J. (2005) Improvement in Colorectal Cancer Survival: A PopulationBased Study. European Journal of Cancer, 41, 2297-2303. http://dx.doi.org/10.1016/j.ejca.2005.01.028

[18] Jemal, A., Siegel, R., Ward, E., Hao, Y., Xu, J., Murray, T. and Thun, M.J. (2008) Cancer Statistics, 2008. CA: A Cancer Journal for Clinicians, 58, 71-96. http://dx.doi.org/10.3322/CA.2007.0010

[19] Yancik, R., Havlik, R.J., Wesley, M.N., Ries, L., Long, S., Rossi, W.K. and Edwards, B.K. (1996) Cancer and Comorbidity in Older Patients: A Descriptive Profile. Annals of Epidemiology, 6, 399-412. http://dx.doi.org/10.1016/S1047-2797(96)00063-4

[20] Coebergh, J.W.W., Janssen-Heijnen, M.L.G., Post, P.N. and Razenberg, P.P.A. (1999) Serious Comorbidity among Unselected Cancer Patients Newly Diagnosed in the Southeastern Part of The Netherlands in 1993-1996. Journal of Clinical Epidemiology, 52, 1131-1136. http://dx.doi.org/10.1016/S0895-4356(99)00098-0

[21] Zeber, J.E., Copeland, L.A., Hosek, B.J., Karnad, A.B., Lawrence, V.A. and Sanchez-Reilly, S.E. (2008) Cancer Rates, Medical Comorbidities, and Treatment Modalities in the Oldest Patients. Critical Reviews in Oncology/Hematology, 67, 237-242. http://dx.doi.org/10.1016/j.critrevonc.2008.02.002

[22] Piccirillo, J.F., Tierney, R.M., Costas, I., Grove, L. and Spitznagel Jr., E.L. (2004) Prognostic Importance of Comorbidity in a Hospitalbased Cancer Registry. Journal of the American Medical Association, 291, 2441-2447. http://dx.doi.org/10.1001/jama.291.20.2441

[23] Geraci, J.M., Escalante, C.P., Freeman, J.L. and Goodwin, J.S. (2005) Comorbid Disease and Cancer: The Need for More Relevant Conceptual Models in Health Services Research. Journal of Clinical Oncology, 23, 7399-7404. http://dx.doi.org/10.1200/JCO.2004.00.9753

[24] Koroukian, S.M., Murray, P. and Madigan, E. (2006) Comorbidity, Disability, and Geriatric Syndromes in Elderly Cancer Patients Receiving Home Health Care. Journal of Clinical Oncology, 24, 2304-2310. http://dx.doi.org/10.1200/JCO.2005.03.1567

[25] Extermann, M., Overcash, J., Lyman, G.H., Parr, J. and Balducci, L. (1998) Comorbidity and Functional Status Are Independent in Older Cancer Patients. Journal of Clinical Oncology, 16, 1582-1587.

[26] Read, W.L., Tierney, R.M., Page, N.C., Costas, I., Govindan, R., Spitznagel, E.L.J. and Piccirillo, J.F. (2004) Differential Prognostic Impact of Comorbidity. Journal of Clinical Oncology, 22, 3099-3103. http://dx.doi.org/10.1200/JCO.2004.08.040

[27] Gooiker, G.A., Dekker, J.W.T., Bastiaannet, E., van der Geest, L.G.M., Merkus, J.W.S., van de Velde, C.J.H., et al. (2012) Risk Factors for Excess Mortality in the First Year after Curative Surgery for Colorectal Cancer. Annals of Surgical Oncology, 19, 2428-2434. http://dx.doi.org/10.1245/s10434-012-2294-6 
Scientific Research Publishing (SCIRP) is one of the largest Open Access journal publishers. It is currently publishing more than 200 open access, online, peer-reviewed journals covering a wide range of academic disciplines. SCIRP serves the worldwide academic communities and contributes to the progress and application of science with its publication.

Other selected journals from SCIRP are listed as below. Submit your manuscript to us via either submit@scirp.org or Online Submission Portal.
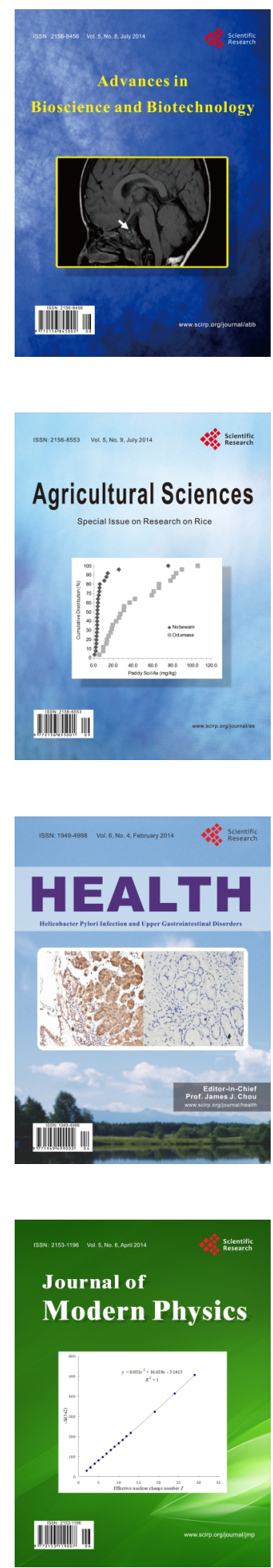
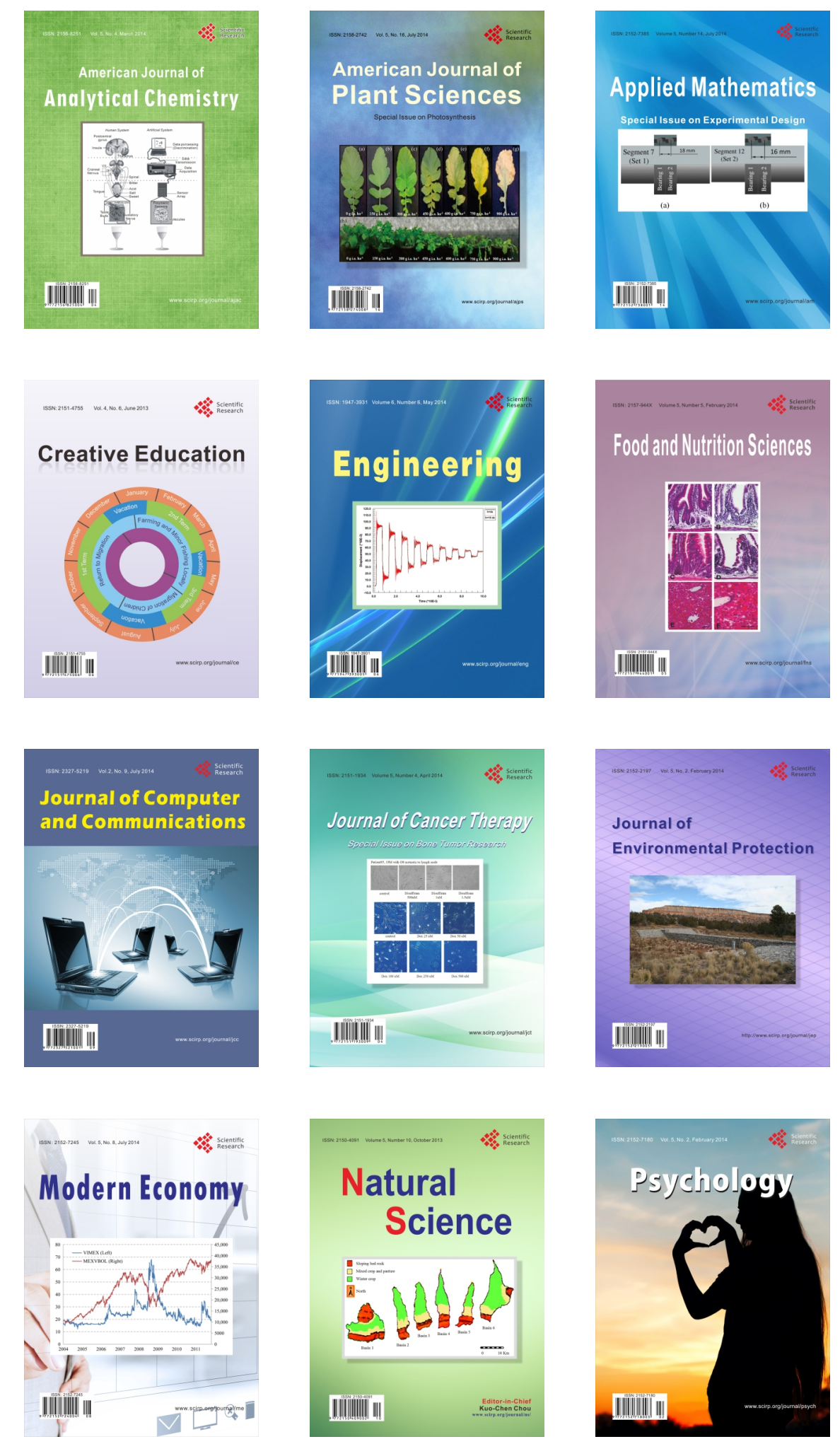